\title{
GOVERNMENT ACTION, SOCIAL CAPITAL AND DEVELOPMENT: REVIEWING THE EVIDENCE ON SYNERGY
}

\author{
Peter Evans
}

\begin{abstract}
Summary. - Instead of assuming a zero-sum relationship between government involvement and private cooperative efforts, the five preceding articles argue for the possibility of "state-society synergy," that active government and mobilized communities can enhance each other's developmental efforts. This article draws on these articles to explore the forms and sources of state-society synergy. I argue that synergy usually combines complementarity with embeddedness and is most easily fostered in societies characterized by egalitarian social structrues and robust, coherent state bureaucracies. I also argue, however, that synergy is constructable, even in the more adverse circumstances typical of Third World countries.
\end{abstract}

\section{INTRODUCTION}

"State-society synergy" can be a catalyst for development. Norms of cooperation and networks of civic engagement among ordinary citizens can be promoted by public agencies and used for developmental ends. Figuring out how such public-private cooperation might flourish more widely should be a priority for those interested in development. The preceding articles by Lam, Heller, Ostrom, Fox, and Burawoy offer an excellent start on this agenda. This essay tries to look across the five articles, highlighting some general findings that resonate across the different settings and perspectives of the individual articles. In addition, I have drawn on some of the other work discussed at the conference where the original versions of the five articles were presented. For example, I will 
make substantial use of Judith Tendler's forthcoming work on "good government" in Northeast Brazil.

First, I examine the structure of synergistic relations, focusing on the distinction between synergy based on complementary actions by government and citizens and synergy based on ties that cross the public-private divide (embeddedness). In the second part of the essay I explore the social and political circumstances that facilitate the emergence of synergy. How crucial is the underlying stock of social capital? How important is the character of the state apparatus itself? What difference do formal political rules or the overall shape of the social structure make? Can synergy be constructed in the short run, or does it require historically deep institutional and normative foundations? Generalizations derived from a small number of cases have to be considered exploratory. Still, common themes derived from such a diverse set of analyses certainly must be considered useful clues by those trying to organize public-private relations more productively, as well as warranting further testing by other researchers. Collectively, these articles raise a welter of new ideas about how and under what circumstances civic actors can more fruitfully engage with public institutions in pursuit of developmental ends.

\section{STRUCTURE OF SYNERGISTIC RELATIONS}

Mutually reinforcing relations between governments and groups of engaged citizens can take a variety of forms. I begin with a simple dichotomy which I think is useful in clarifying what we mean by synergy-an analytical distinction between complementarity and embeddedness. The two concepts not only imply different forms of synergy, but also different connections between the idea of synergy and prior theories of relations between public and private institutions.

Complementarity is the conventional way of conceptualizing mutually supportive relations between public and private actors. It suggests a clear division of labor, based on the contrasting properties of public and private institutions. Governments are suited to delivering certain kinds of collective goods which complement inputs more efficiently delivered by private actors. Putting the two kinds of inputs together results in greater output than either public or 
private sectors could deliver on their own. The idea of complementarity fits nicely with existing paradigms in institutional economics and public administration and forces no rethinking of the public-private divide.

The idea that synergy may be based on "embeddedness" - that is, on ties that connect citizens and public officials across the publicprivate divide-is more novel. Can networks which trespass the boundary between public and private be repositories of developmentally valuable social capital rather than instruments of corruption or rent-seeking? Despite the difficulties it creates for conventional wisdom, the evidence that has been presented in these articles suggests that the permeability of public-private boundaries must be acknowledged as an inescapable part of many developmentally successful programs.

Acknowledging embeddedness does not make analysis of complementarities obsolete. To the contrary, complementarity and embeddedness turn out to be mutually supportive. Most concrete cases of synergy involve combinations of complementarity and embeddedness. The aim of separating the two is not to privilege one over the other, but to get better analytical purchase on the complexities of synergistic relations.

Complementarity is given a new dimension when social capital is included along with goods and services as a desired outcome of public-private cooperation. New research on states and the formation of social capital suggests new kinds of complementarities and innovative ways of seeing traditional complementarities.

The most universally acknowledged kind of complementarity is exemplified in the quote from Nugent (1993) cited in the introduction. Effective states deliver rule-governed environments which "strengthen and increase the efficiency" of local organizations and institutions. The state's contribution to social capital is general and from a distance. Productive informal ties, like market exchange, require a basic ambience of rule-governed behavior. The state provides the necessary ambience, but public agencies are not directly linked to societal actors.

Traditional analysis of the benefits of a rule-governed environment-from Weber to Douglass North-emphasizes its role in eliciting entrepreneurial behavior from economic elites. The work being discussed here suggests that the "rule of law" may be even more 
important as a complement to the efforts of less privileged groups to organize themselves. Both Heller and Fox argue that the provision and enforcement of universalistic rules is an invaluable organizational resource for the less privileged. ${ }^{1}$ Fox underscores the centrality of simple legal norms such as freedom of assembly and association in making civic organization possible for indigenous peasants. Heller sees "drawing traditionally disenfranchised workers within the purview of the law" as critical to the process of mobilization in Kerala. Conversely, as O'Donnell (1993: 1365) has eloquently argued, the destruction of "the state as law" in many parts of Latin America has led to an "angry atomization of society" which leaves no space for self-organization at the bottom.

Complementarity based on the public provision of intangibles can also take forms quite independent of the provision and enforcement of rules. The creation and diffusion of new knowledge by agricultural extension services is a standard example. More novel examples of complementarity based on the provision of intangibles are offered by Tendler in her recent (forthcoming) work on "good government" in Northeast Brazil. ${ }^{2}$ Tendler makes the point that another kind of intangible collective good with very large economies of scale is media publicity. Because media publicity is subject to manifest economies of scale, it is the kind of public good that it makes sense for the state to provide. One of the most important aspects of this complementary input was that it enhanced the extent to which government programs were able to combine social capital formation with the delivery of services. In Ceará's successful preventive health program, the state government's blitz of positive media publicity bolstered the health agents' sense of "calling" and made them more willing to engage in the kind of diffuse public service that helped generate new relations of trust between them and the community. It also affected the way in which they were viewed by members of the community, again increasing the likelihood of relations of trust. Similar effects were observed in the case of agricultural extension workers trying to organize drought relief. According to Tendler (forthcoming: 116; see also Tendler and Freedheim 1994),

As with the health agents, the state government's actions [in promoting a supportive media campaign] elicit public-minded be- 
havior by creating a strong sense of "calling" around particular public jobs and civic responsibilities .

Complementarity of a more prosaic and tangible variety can also play a significant developmental role. Irrigation is the classic case, in both historical and contemporary analysis. Contemporary work, however, adds the positive impact on social capital formation as one of the important byproducts of complementarity. This perspective extends the standard analysis of public goods to include the possibility that provision of such goods, in addition to facilitating private production of conventional goods (crops in this case), may also contribute to "enhancing farmers' capability and willingness to relate to, and to work with, one another" (Lam 1994: 288). Efficient provision of the tangible main facilities and channels has the intangible consequence of making it more worthwhile for farmers to organize themselves. Other kinds of tangible complementarities can also stimulate social capital formation. In Fox's discussion of "reformists" and peasant organizations in rural Mexico, one of the state's contributions to "scaling up" peasant social capital is simply providing transportation so that peasants from different local areas can get together.

Looking at these examples, it is clear that complementarity is not just about government providing inputs that its scale and bureaucratic organizations allow it to provide more effectively and leaving it to citizens to do the rest. Complementarity supports dayto-day interaction between public officials and communities, which is in turn essential to organizing complementarity. In addition to promoting social capital formation in civil society, complementarity supports embeddedness.

Embeddedness complicates the analysis of synergy. If synergy depends on day-to-day public-private interactions and the norms and loyalties that build up around them, then its institutional forms become more complex. Unfortunately for analytic simplicity, however, embeddedness appears to be just as common a feature of synergy as complementarity.

Again, irrigation provides a nice way to start. In Lam's earlier (1994) analysis of Nepal, complementarity without the intrusion of public officials at the local level seemed to be the ideal. Farmers needed inputs that they could not supply themselves in order to 
make it worth their while to organize, and it was also helpful if the state provided intangible collective goods in the form of legal recognition of local farmers' groups. The state was useful as long as it kept out of the day-to-day operation of irrigation systems at the local level. Direct involvement of the state bureaucracy in the operations of local systems undercut the development of the collective institutions that farmer-managed systems depended on and reduced the likelihood of effective water delivery. The lesson seemed to be that the state can help most by providing inputs that local people cannot provide for themselves and then maintaining a "hands-off" stance with regard to activities that are within the scope of local action.

Lam's article here on Taiwan presents a very different kind of story. Taiwan's irrigation system operates much more efficiently and effectively than the one Lam studied earlier in Nepal, ${ }^{3}$ but it is certainly not an instance of "hands off" complementarity. Lam's work confirms Moore's earlier assessment (1989: 1748,) that "enmeshment" in the form of a "dense network of social relationships which exist among IA staff and IA members" is the key to the system's effectiveness at the local level. According to Moore (1989: 1742), "IAs are overwhelmingly staffed by people who were born in the locality, have lived there all their lives, and, in many cases, also farm there." Therefore, "IA staff are so much part of local society that they can neither escape uncomfortable censure if they are seen to be conspicuously performing poorly, nor ignore representations made to them by members."

Lam's account further spells out the multifaceted set of ties which bind together local public officials and local farmers. ${ }^{4}$ His analysis makes clear the extent to which those who make their careers the local field offices rely on the experience and local knowledge of the farmers to allocate water among the fields, to carry out local operations and maintenance, and to provide the voluntary labor and voluntary monetary "chip-ins" which "were important sources of resources for irrigation management at the local level." At the same time, local farmers depend on their public sector counterparts. The local field station is responsible for integrating local needs into the overall plan for the entire irrigation association and, even more important, for making sure that the promised water is actually delivered to the local area. Farmers and local officials are engaged in a shared project aimed at making sure that enough water reaches 
their area at the right time. There is a division of labor, but it is among a set of tightly connected individuals who work closely together to achieve a common set of goals.

Once again, Tendler's work in Northeast Brazil reinforces the insights gained from East Asian irrigation systems. The health care program she describes in Ceará epitomizes the way in which embeddedness plays a role in the success of public programs. Creating new ties between 7,000 newly hired health agents and their communities was the key to the health program's success. Starting out in a civic climate in which people were reluctant to even open their doors to anyone working for the government, ${ }^{5}$ the new health agents made building relations of trust between themselves and their "clients" a central part of their jobs. To this end, they even helped with mundane household tasks without direct relation to health (e.g., cooking or cutting a baby's hair). According to Tendler (forthcoming: 76), "they saw their clients not only as subjects whose behavior they wanted to change, but as people from whom they wanted respect and trust." Not surprisingly, the health agent's approach generated reciprocal attitudes, with clients describing them as "true friends." Individual ties helped generate in turn a generalized commitment to the community. Tendler reports (forthcoming: 73) that "health agents took on, of their own accord, community-wide activities meant to reduce public health hazards-in addition to their job of visiting households." As one health agent put it, "I was ready to leave and look for a job in São Paulo, but now I love my job and I would never leave-I would never abandon my community."

In Tendler's description of Ceará's health campaign, as in Lam's description of the Taiwanese irrigation system, social capital is formed by making some who are part of the state apparatus more thoroughly part of the communities in which they work. The networks of trust and collaboration that are created span the public-private boundary and bind state and civil society together. Social capital inheres, not just in civil society, but in an enduring set of relationships that spans the public-private divide.

The interweaving of ties across the public-private divide to create developmentally effective social capital can even characterize what are usually thought of as institutions rooted strictly in civil society, like Grameen Banks. In May 1992, a Grameen Bank-type rotating credit association was begun in the environs of Ho Chi Minh 
City. Participation was limited to poor households, and 95 percent of the participants were women. They used the loans for working capital in petty trading ventures (e.g., selling vegetables) or to buy equipment for craft production (e.g., sewing machines). The loans had a substantial impact on the women's income earning capacity, and the reported repayment rate on the loans was an astonishing 100 percent. $^{6}$

Such results are not, of course, unusual for Grameen Bank-type projects. ${ }^{7}$ What makes this project interesting and relevant to the analysis of synergy is that it was organized by the Institute of Economic Research (IER), an agency of the city government of Ho Chi Minh City (with support from an international nongovernment organization). The IER enlisted the support of the people's committees (local government) in the villages covered by the scheme but continued to provide training and technical support. The local village secretaries provided the organizational skills and energy that actually got the project rolling. The organization of the individual credit groups depended on pre-existing ties (friends, relatives, etc.), but the initial organization of the scheme as well as its organization and administration depended on the interaction of local government staff and officials and their relationships with the local women who became members and group leaders. Adding concrete ties across the state-society boundary to pre-existing kin and friendship ties helped transform traditional ties into developmentally effective social capital.

Embeddedness is not just a feature of developmentally effective relations between public agencies and the powerless. It is even more pervasive in successful projects that join the state with elite actors. The "local state corporatism," which Burawoy, following Oi, sees as underpinning China's surprising rates of rural industrial growth, depends on a set of local ties which bind local state officials and nascent entrepreneurs around a joint project of rural industrialization. Oi notes that in most of the localities where she has done fieldwork, "it is the local party bosses-the first party secretary of the county, township or village-who are at the helm of the drive for economic development" (Oi 1992: 124). Not only are the ties between local enterprise managements and local officials important, but also the web of relations that allows local officials to work through officials and agencies in the central state apparatus to gain access to 
credit and scarce raw materials that local entrepreneurs need (Oi 1992: 120-21).

The central role of ties that cross public-private boundaries in China's "transition" success story echoes the pivotal role of embeddedness in the biggest capitalist success story of the twentieth century-the transformation of the economies of East Asia from lowproductivity agrarian backwaters to the most rapidly growing industrial economies in the world. Even the official World Bank interpretation (1993) concedes that state/society linkages played a central role in this "East Asian Miracle." Institutional descriptions of East Asian industrialization, from Johnson's (1982) classic work on Japan to Amsden (1989) and Robert Wade (1990) on the East Asian newly industrializing countries (NlCs), paint a picture of dense networks that span public-private boundaries. From Okimoto (1989) to the World Bank (1993), analysts stress the dense networks of ties that connect state agencies and private capital. From joint business-government "deliberation councils" to "the maze of intermediate organizations and informal policy networks where much of the time consuming work of consensus formation takes place" (Okimoto 1989: 155), it is social capital built in the interstices between state and society that keeps growth on track. This profusion of concrete ties between officials in organizations such as Taiwan's Industrial Development Bureau, Japan's MITI, or Korea's Ministry of Communications and those who manage private industrial corporations generates in turn a "joint project" of industrial transformation (Evans 1995).

In these archetypal capitalist successes, as in China's would-be market economy, the social capital that is most critical to the outcome is formed once again in networks that are neither public nor private but fill the gap between the two spheres. ${ }^{8}$ Far from being a pattern that emerges only when the state develops ties to the less privileged or during the transition from nonmarket to market-based economic relations, synergy based on embeddedness is the essence of the most important contemporary instances of market success.

The centrality of embeddedness to synergy across a range of different settings is undeniable, but none of this negates the importance of complementarity. Instead, this multiplicity of examples should be taken as a reminder that even the most obvious division of labor must be sustained by shared orientations and concrete interactions among the actors involved. A better sense of how comple- 
mentarity and embeddedness can come together is the key to understanding synergy.

Embeddedness and complementarity are not competing conceptions of synergistic relations but are themselves complementary. A few examples will suffice to make the point. "Coproduction," which forms the conceptual framework for both Lam and Ostrom's analysis, sets out the interdependence of complementarity and synergy most clearly. ${ }^{9}$ In the coproduction model, complementarity creates a basis for productive interaction, but without embeddedness the potential for mutual gain is hard to realize.

As Ostrom's production functions (Figures I and 2) show graphically, complementarity is the essential prerequisite of coproduction. When public agents and citizens have sufficiently different (but equally necessary) kinds of inputs, they can produce more efficiently by combining their efforts than by either producing everything privately or everything publicly. Complementarity is the precondition for coproduction. Without complementarities there would be few incentives (other than rent-seeking) for trying to organize collective actions across the public-private divide. Nevertheless, production functions convey only the complementarity half of the coproduction story. The embeddedness half of the story comes across only in concrete examples.

Ostrom's sewer condominium case illustrates the point. Complementarity was clear. The technology of producing trunk sewer lines was beyond the collective efforts of local neighborhoods, so neighborhoods had to rely on government to produce trunk lines. By the same token, public sector fiscal problems put the resources necessary to deliver the entire system out of reach of the government. Without citizen collaboration the full network would not be built. This, however, is only the complementarity half of the story. Complementarity created the potential for synergy but not the organizational basis for realizing the potential. Embeddedness in the form of direct involvement of the public officials was a key component in getting citizen efforts organized and sustaining citizen involvement. The organizational "start-up costs" of setting up neighborhood meetings, explaining options, and mediating conflicts required substantial time and effort on the part of public officials. Likewise, once the sewer systems were constructed, monitoring and maintenance required continuous face-to-face interaction between an ongoing, fa- 
miliar set of public agency staff and collaborating neighborhoods. In short, a relationship very much like the one that unites farmers and local irrigation staff in Taiwan delivered sewers to urban neighborhoods in Northeast Brazil.

Irrigation systems, like sewers, are characterized by complementarity as well as embeddedness. The role of embeddedness in the Taiwanese case has already been highlighted; the importance of complementarities needs to be underlined as well. Dams, reservoirs, and other "lumpy collective goods" are provided by state agencies that are quite separate from the embedded Irrigation Associations. As Lam points out, one of the reasons for Taiwan's success is that, in contrast to South Asian irrigation systems, it has left responsibility for the construction of major irrigation projects in the hands of a separate organization, so that operation and maintenance do not become "stepchildren" in a construction-dominated bureaucracy. Here again, Lam's analysis parallels that of Moore (1989: 1741), who notes that, "The key feature is the institutional separation of major irrigation construction, which is the responsibility of national agencies, from routine maintenance and operation of irrigation systems."

Even in the maintenance and operation of the system, there is clear recognition of the complementarities between what the public agencies can do and what self-organized citizens can do. The bureaucratic hierarchy constructs the overall plan of water delivery (after the basic inputs of information have been constructed jointly by local officials and farmers). The organization of the system recognizes that trying to have local communities settle on an overall plan would lead to a cumbersome, ineffectual political process in which local communities were forced to make decisions involving the unfamiliar circumstances of other areas. By the same token, state officials do not infringe on the role of the water guards at the village level or become involved in micro-level allocational decisions among farmers. To do so would stretch even the very well-organized Irrigation Association bureaucracies beyond their capacity, and they still would not be able to replicate the efficiency of community initiatives. Everyone realizes that even local officials with long tenure in a particular area cannot replicate the local knowledge (social as well as topographical) of the water guards and irrigation group leaders. In sum, intimate interconnection and intermingling among public and private actors is combined with a well-defined complementary division of labor 
between the bureaucracy and local citizens, mutually recognized and accepted by both sides. Tendler's health campaign is yet another example of complementarity combined with embeddedness. The Ceará state government's media campaign was a very useful complementary input, but without the thousands of day-to-day interactions between health care workers and community members to give it substance, the media campaign would have been fruitless. If the government had limited its role to the provision of the complementary input and assumed that local citizens would provide the appropriate responses without the involvement of public sector workers in the construction of a set of reinforcing ties, the campaign would almost certainly have failed.

In the end, the analytical distinction between complementarity and embeddedness is useful primarily in that it reminds us to look for both elements. There may be cases in which synergy is created solely on the basis of complementarity. Or, though this seems even less likely, cases where synergy is built around network connections which do not involve complementarity. Nonetheless, the best way to understand synergy is as a set of public-private relations built around the integration of complementarity and embeddedness.

This preliminary description of the forms of synergy is useful in thinking about how synergy works in practice, but it does not illuminate the social and political conditions that make synergy possible in the first place. To explore the origins of synergistic relations it is necessary to look more broadly at the circumstances under which

synergy has emerged, searching for commonalities across different contexts.

\section{CONTEXT AND CONSTRUCTION IN THE CREATION OF SYNERGY}

The most basic issue in analyzing the origins of synergistic relations is the question of endowments versus constructability. Does the possibility of synergy depend primarily on sociocultural endowments that must be taken as givens? Or can the application of imaginative organizational arrangements or institutional "soft technologies" produce synergy over relatively brief periods of time? If synergy is an outcome that depends on the prior existence of social and cultural 
patterns historically rooted in particular cultures and societies, then it may well be out of reach for most groups. A "constructability" perspective is more optimistic. Synergy becomes a latent possibility in most contexts, waiting to be brought to life by the institutional entrepreneurship. Optimistic assumptions, precisely because they are attractive, must be approached skeptically. Assuming constructability if endowments are really the key would only produce failure and frustration. Nonetheless, if possibilities for construction exist, they should be exploited.

The most obvious endowment that might set limits on synergy is the stock of social capital within civil society, but there are others. The relevant properties of government institutions may take decades or generations to change, in which case they are best considered as endowments. Likewise, basic, hard-to-change features of the social structure, like the degree of inequality, may put synergy out of reach for certain societies. The possibility of synergy might be also preconditioned on the prior existence of particular kinds of political regime. Singly or in combination such factors must constrain the possibility of constructing synergistic relations. The question remains: how much room is left for agency?

In order to assess the relative weight of endowments and constructability, I begin with a look at the role of endowments of social capital in civil society, then move to a focus on administrative structures and the question of whether robust, efficacious bureaucracies constitute prerequisites for synergy. I then turn to politics and social structure and the ways in which political regimes and the basic patterns of interest conflicts in society impinge on the possibility of synergy. Finally, I return to the issue of constructability and whether we can point to any "soft technologies" of institutional change that enhance the possibilities for joint projects that bring together government and civil society in the short run.

Endowments of social capital are obviously crucial to synergy. Putnam's (1993a) original analysis of the Italian case suggested that stocks of social capital accumulated over long periods of time (perhaps hundreds of years) were the crucial ingredient in creating the "virtuous circle" in which civic engagement nurtured good government and good government in turn fostered civic engagement. The question remains whether in most Third World settings the requisite social capital is in such short supply as to exclude the possibility of 
synergy or whether the norms and networks that characterize "normal" Third World communities constitute sufficiently fertile ground for the construction of developmental projects that span the publicprivate divide. The cases analyzed here suggest that prior endowments of social capital are not the key constraining factor. The limits seem to be set less by the initial density of trust and ties at the microlevel and more by the difficulties involved in "scaling up" micro-level social capital to generate solidary ties and social action on a scale that is politically and economically efficacious.

Starting once again with Taiwan's irrigation system, it is hard to make the argument that the system's unusual efficiency derives from historically exceptional levels of social capital in Taiwanese rural communities. Lam is quite explicit about this, saying "farmers in Taiwan do not stand out as having unusual levels of trust and solidarity." This is not to say that solidary community ties are irrelevant to the local functioning of the irrigation system. Water guards and irrigation group leaders could not perform their functions in the absence of supportive community norms. The point is rather that such community norms are probably no stronger in Taiwan than they are in Nepal, where irrigation is a much more problematic affair.

The same argument applies even more strongly to the Northeast of Brazil, which is the site of both Ostrom's and Tendler's examples of synergy. Neither Tendler's rural communities nor the city neighborhoods in Recife that are the site of Ostrom's sewer condominiums are known as historically exceptional repositories of civic engagement. Ethnographic descriptions suggest that Northeast Brazil is as prone to conflict and suspicion as most areas of the Third World. Nor, for that matter, did exceptional endowments of social capital appear to play a role in the successful Vietnamese Grameentype bank mentioned earlier. In all of these cases, cooperative patterns of interaction among friends, kin, or neighbors no doubt antedate and facilitate particular instances of synergy, but the stock of social capital is not exceptional.

Heller makes the point more forcefully. Disputing analyses which see Kerala's extraordinary levels of contemporary mobilization as the result of the area's historic "proliferation of community associations," Heller argues that traditional associations based on caste and community ties could never have produced the kind of developmental transformation that Kerala has experienced. In fact, 
as he points out, the natural outcome of a "vigorous civil society rooted in interests bounded by parochial loyalties" is not development but the kind of "demand overload" that has been such a crippling problem for India as a whole. Kerala's tradition of caste and community activism provided a useful foundation for subsequent mobilization, but in order to produce the results that were achieved the activist tradition had to be harnessed to a more universalistic set of identities. Translating social ties from engines of parochial loyalties into vehicles for more encompassing forms of organization was the real key to synergy.

Fox places the strongest emphasis on historical endowments of social capital, noting that "the overall degree of survival of horizontal community organization and norms of reciprocity in indigenous Mexico is quite remarkable." Nevertheless, Fox, like Heller, emphasizes that the key problem is not social capital at the level of local communities but rather "scaling up" such personal and community ties to form organizations that can be developmentally efficacious. To be politically effective, Fox argues, autonomous peasant organizations have to have a regional scope, bringing internally solidary communities together with a broad set of other villages who share similar interests.

As in Heller's case, Fox points to the role of state actors in translating local networks into developmentally relevant "scaled-up" organizations. Just as in Kerala, "reformists" within the state apparatus were crucial to the process of translating parochial loyalties into more encompassing forms of organization. Fox recounts an iterative pattern of interaction between state social policy initiatives and social mobilization. Each round brought higher levels of popular mobilization. In the first case (PIDER) state-sponsored rural development organizations "successfully organized peasant protest against regional bosses for broader distribution of credit and fertilizer" (Fox 1994: 162-63). The second (CONASUPO) was even more surprising in its effects: "For one to two million of Mexico's most impoverished rural people, the food councils [created by CONASUPO] were among the first genuinely mass-based, regionwide representative organizations of any kind" (Fox 1994: 165). The third cycle (PRONASOL) continued the process of "'objective alliance' between social movements and reformists" (Fox 1994: 165) through which reformist social programs "offered political and economic resources that fostered the 
consolidation of growing representative and autonomous social organizations"(Fox 1994: 177).

Fox's reformists in the state apparatus support and transform mobilized groups in civil society much in the same way (if not as thoroughly and unreservedly) as party activists and their government allies did in Kerala. Rural Mexico is not, however, Kerala. While parts of the state were "coproducing" autonomous associations of rural peasants, other parts of the state were working with rural elites to suppress the same organizations. Reformists were always engaged in an implicit or explicit struggle against politically authoritarian groups within the state apparatus and their private allies. The state of Chiapas offered a particularly telling example. Threatened by the state reforms in the National Indigenous Institute (INI), "the governor jailed three top INI officials on trumped-up charges of fraud." Seeing their state allies in jail, "autonomous indigenous organizations marched to defend them" (Fox 1994: 175-76).

None of these examples negate the importance of micro-level social capital in the construction of synergy. Ties among friends and neighbors based on trust and rooted in everyday interactions are essential foundations. Without them there would be nothing to build on. The key point is that such ties seem to be a resource that is at least latently available to most Third World communities. Based on these cases, it seems reasonable to argue that if synergy fails to occur, it is probably not because the relevant neighborhoods and communities were too fissiparous and mistrustful but because some other crucial ingredient was lacking.

The most obvious candidate for the missing ingredient is a competent, engaged set of public institutions. If synergy can regularly emerge out of communities that seem quite ordinary in terms of their stock of social capital, but governments vary dramatically in terms of their ability to act as counterparts in the creation of developmentally effective civic organizations, then perhaps the limits to synergy are located in government rather than in civil society. Fox's Mexican case shows that even a somewhat schizophrenic government apparatus can occasionally produce instances of synergy, but the character of the state apparatus may still be the weak link in the generation of synergistic relations.

Government organizations vary fundamentally across countries in ways which shape the possible forms of state-society relations. The 
nature of the connection is, however, less obvious than it might appear. There are at least two competing perspectives on what kind of government organization makes for the most effective relations between state and society. Some analyses focus on the importance of corporately coherent Weberian bureaucracies in making sure that embeddedness does not degenerate into clientelism (e.g., Evans 1995). Others focus on the importance of decentralization and opening up bureaucratic hierarchies to inputs from below. There is support for both perspectives in the material considered here and some hints as to how the two views might be reconciled.

Undoubtedly, the absence of coherent, dependable public institutions makes synergy harder. Burawoy's analysis of the demise of the woodworking conglomerate in Komi illustrates the point. The demolition of the Russian state left the woodworkers of Komi without an effective public sector counterpart. ${ }^{10}$ Consequently, self-organization moved in the opposite direction from the trajectory that Heller reports from Kerala. Divisive interests prevailed and the gains from interdependency were ignored. Whatever social capital existed in the prior woodworking conglomerate was dissipated, and individual companies were left to the mercy of global commodity markets. The Chinese case makes the converse point. While Russia's government was dissolving into disarray, China's retained sufficient coherence to purposefully restructure the system of incentives at the local level in a way that promoted self-organization and entrepreneurship.

The civic advantages of having a coherent government bureaucracy are conveyed even more clearly in Lam's analysis of Taiwanese irrigation. A tightly organized and quite traditional bureaucratic hierarchy provides a supportive carapace for the self-organization of the farmers. The robustness of government organization gives the farmers confidence that the higher levels of the apparatus will in fact deliver the water they have been promised and increases the incentive for forward-looking cooperation at the local level. At the same time, a well worked-out hierarchical division of labor within the bureaucracy leaves farmers and local officials free to work out their problems at the local level without interference from above.

The importance of robust bureaucratic structures is amplified in analyses of East Asian industrialization. When individual officials are enmeshed in a set of close relations with elites who command vast private resources, attractive opportunities for rent-seeking are inevi- 
table. Unless such opportunities are constrained by powerful internal norms and a dependably rewarding system of long-term career benefits, corruption is indeed likely to become the prime consequence of embeddedness. ${ }^{11}$ In the East Asian cases, careful attention has been paid to the traditional Weberian requisites of bureaucratic organization. Public institutions are characterized by traditional Weberian features such as meritocratic recruitment, good salaries, sharp sanctions against violations of organizational norms, and solid rewards for career-long performance. Corruption is still common, but it has not been allowed to overwhelm the joint public-private project of industrialization.

Cases in which traditional bureaucratic forms are vehicles for synergy must, of course, be juxtaposed with the more familiar story in which bureaucracy is the enemy of both social capital and development. Ostrom's story of Nigerian primary education is a paradigmatic example, so much so that it is worth breaking down this case of "anti-synergy" into its constituent elements. To begin with, there is no complementarity. Bereft of resources itself, the state provides little in the way of tangible support to local public institutions. To make matters worse, bureaucratic organization, instead of being used as the rationale for a liberating hierarchical division of labor, as in the Taiwanese case, is interpreted as demanding a uniform, simplistic application of inflexible rules which leave no room for initiative or imagination on the part of either local officials or their counterparts in civil society. This kind of bureaucracy eliminates the possibility of synergy.

On reflection, this crude exercise of bureaucratic power is, like the absence of material benefits, an indication of the state's poverty-in this case its organizational poverty. Uniformity is the simplest rule; constructing the kind of intricate interplay of hierarchy and latitude that characterizes a Taiwanese irrigation association requires much more capacity and sophistication. The overcentralized Nigerian education ministry actually demonstrates the same lesson as the East Asian cases. Robust, sophisticated public institutions are an advantage both in the formation of local social capital and in the pursuit of developmental ends, not because they are instruments of centralization but because they are capable of formulating more nuanced ways of distributing power and therefore of supporting decentralization and openness to local self-organization. 
Another aspect of the Taiwan/Nigeria contrast takes the analysis down a different road. Alongside the question of bureaucratic structures and rules there is the question of public sector attitudes. Ostrom suggests that one of the reasons public bureaucracies are ineffective is that "Public sectors typically rely on incentive systems that send very weak signals about performance to staff." Put another way, many public bureaucracies give public sector workers little reason to pay attention to the people they are serving. While the articles I am drawing on here do not contain much direct evidence on the attitudes of public sector staff toward the communities they work with, ${ }^{12}$ gross differences are evident. In Kerala there is a strong identification of party and state officials with their constituents. In the East Asian cases constituents are also important. Lam reports that "the image that farmers are the boss of the IA is very clear in the minds of IA officials." The importance of private sector entrepreneurs to the bureaucrats that worked with them in creating the East Asian miracles goes without saying. In Ostrom's discussion of Nigerian primary education, on the other hand, bureaucratic behavior radiates indifference. Finally, in Fox's Mexico, it is clear that in the eyes of a large number of state officials, nonelite constituents are the enemy. This range of attitudes is not just a reflection of differences in administrative structures or governmental competence. It is a reminder that we cannot analyze synergy without considering questions of politics and interests.

Politics and interests often get relegated to the background in discussions of social capital. Most discussions implicitly assume a group, relatively homogeneous in terms of its interests, whose members must overcome collective action problems in order to realize their shared interests. Shared norms of trust and cooperation are a means of overcoming the collective action problems. If a community is riven by conflicting interests, the nature and meaning of social capital becomes more complicated.

The idea of synergy, as it has been developed to this point, implicitly takes the assumption of homogeneous interests further by assuming that public sector actors share interests with their constituents. In fact, the degree to which interests are shared across the public-private divide varies substantially from case to case and plays a central role in determining the potential for synergy. Introducing the question of conflicting interests raises in turn the question of 
whether conflicts are fought out in open political competition or contained by repression. Political regimes no less than bureaucratic structures condition the possibility of synergy and social capital formation. The question of political competition is the best place to begin the discussion.

In the cases reviewed here, political competitiveness seems to have a salutary effect on possibilities for synergy . Heller emphasizes the centrality of persistent political competitiveness in sustaining the commitment of parties (whether in or out of government) to mobilization and the construction of encompassing organizations among subordinate groups. Tendler emphasizes the connection between the reinitiation of democratic elections in Brazil and the government of Ceará's new-found enthusiasm for building connections with common citizens. Even in the Taiwanese case, Lam argues that, despite one-party rule at the national level, political competitiveness (among factions) is quite pervasive at the local level and helps to generate pressure on the IAs to remain responsive to the interests of local communities.

Before accepting unreservedly the idea that political competitiveness enhances synergy, some caveats are in order. First, in order for political competition to have positive effects, it must be constrained by mutually accepted ground rules that channel political energies into efforts at mobilization or attempts to convince the citizenry of governmental efficacy. Second, there is an interaction between the administrative issues discussed above and the consequences of political competition. Incentives derived from political competition are hard to actualize without an adequate administrative infrastructure. Finally, the incentives generated by political competition are not necessarily the most salient factor in motivating specific efforts to "coproduce" particular goods or services. I will start with the motivations of public sector workers and work back to the question of "rules of the game."

At least in the cases examined here, the public sector workers who build the social and organizational infrastructure of synergy "on the ground" appear more motivated by a desire to realize their own organizational objectives than by an interest in preserving the standing of a particular party or faction. The satisfactions of the Brazilian engineer that designed the condominium sewer idea were technocratic rather than political. Tendler's health care workers, ex- 
tension agencies, and small business consultants did not see the payoff to their efforts as justified primarily by their impact on the interests of a particular political faction. The technocrats in Japan's MITI or Taiwan's Industrial Development Bureau could hardly be more different from Tendler' $s$ health agents, but they share a relative disinterest in contributing to the political advantage of particular political factions.

None of this is to say that political competition conveys no benefits to public officials and organizations trying, for whatever reason, to deliver services. Political competitiveness is useful first of all because it contributes to a climate in which citizens count. The effective delivery (or coproduction) of public services is only valued if citizens' reactions make a difference in the eyes of government leaders. In short, political competition helps mitigate what Ostrom calls the "signals problem" that has already been mentioned. Finally, political competition is important because it helps check the ability of individual members of the elite to interfere with efforts to foster social capital among the less privileged.

Just as the presence of engaged public agencies may allow synergy to proceed in concrete cases independently of incentives generated by political competition, the positive possibilities that flow from political competitiveness are likely to be sterile if public institutions are organizationally incapable of delivering what people need. PostSoviet Russia allows more political competition than China, but the ineffectual Russian state provides no dependable vehicle to "deliver the goods." Individual state officials have no reason to believe either that their efforts will produce the intended effects, or that producing the intended effects will be rewarded by their superiors. In short, without an effective administrative apparatus, the more positive orientation toward citizens associated with political competition is hard to translate into results .

The rules of the game issue is perhaps the most important caveat with regard to political competition. As Fox underscores, entrenched elites (inside and outside of government) are likely to interpret increased political competitiveness as a threat and respond with repression. Without that quintessential complementary good-the rule of law-private thugs and official means of repression commandeered for particularistic ends become the principal tools of political competition. Unless force and corruption can be 
made marginal to the repertoire of competitive strategies, increased political competition has perverse effects. Once again, Kerala provides a nice counterpoint to rural Mexico. In Mexico the official means of violence are routinely diverted to pursue essentially private ends. In Kerala, despite the anti-Communist bias of the national government of India, the Indian state was unwilling to allow Kerala's landlords to commandeer the official means of violence to counteract mobilization. Class warfare was fought on the terrain of ideology and organization, which meant positive spillovers for both social capital formation and synergy.

The forms and nature of political competition depend, of course, not only on the effective normative context but also on the nature of underlying social conflicts. Looking at the cases under review here, it is clear that a relative equality of circumstances is an advantage, not just in building social capital, but also in creating societal foundations for synergistic relations with the state. From Taiwan to Kerala, relatively egalitarian social structures are as much of an advantage for synergy as is political competitiveness.

Taiwan enjoys, of course, one of the lowest Gini indexes in the Third World, and its rural sector is internally more egalitarian than the overall society. Building solidary organizations oriented toward increasing output in an agricultural sector "mainly comprised of small family-owned farms" where landlords have "virtually disappeared" (Lam) is a qualitatively different task than trying to do the same thing in rural Mexico, where large landowners dominate an excluded peasantry. There are economically advantaged "local notables" in Taiwanese farming communities, but their income and status do not derive from controlling the land or labor of their neighbors. Instead, they are likely to see their neighbors as a potential political base. Lam contrasts this situation with the typical South Asia context, where divisions between rich and poor agriculturalists are the source of sharp conflicts around the management of irrigation.

Kerala post-land reform is also exceptionally egalitarian. This point has been made repeatedly with respect to agriculture. Heller extends it to industry. He points out that one of the things that makes industrial relations in Kerala exceptional is that the vast gap that in the rest of India separates the organized sector from the informal sector has been largely closed in Kerala. Gaps among different cate- 
gories of workers within each sector have also been substantially narrowed. In such a context, generalized mobilization and the construction of synergistic relations with the state flourish, in sharp contrast to the rest of India, where, as Heller puts it, "A fragmented and dependent labor movement has spawned atomized and disaggregated strategies and . . labor management relations in general have become increasingly chaotic and ungovernable."

These cases replicate on a societal scale what is also true in microcosm in the more specific studies of Ostrom and Tendler. The societal context of Northeast Brazil is starkly inegalitarian, but the groups which become organized and connected to state initiatives in the examples offered by Ostrom and Tendler share similar circumstances and problems. In Tendler's rural communities and Ostrom's urban neighborhoods, the constituencies involved share relatively homogenous interests with respect to the problems they are trying to solve. ${ }^{13}$

To the extent that egalitarian social structures facilitate synergy, social structure may be an important obstacle to constructing synergistic relations, or at least in constructing such relations with subordinate groups. Unfortunately, rural Mexico is more typical than rural Taiwan or Kerala. In most Third World countries, the interests of the privileged intrude fundamentally on relations between the state and less privileged groups. The ways in which public officials deal with elites and the conflicting interests that separate elites from the rest of the citizenry have to be factored into the equation.

In rural Mexico, Fox sees the state apparatus as generally allying itself with private elites at the expense of the peasantry. What needs to be explained then is why, even in this class-divided society, there are so many significant exceptions in which state actors ally themselves with subordinate groups. Why are there "reformists" who foster social capital formation among the oppressed, not just in opposition to the interests of landowners, but at some risk to their own positions within the government?

To begin with, state actors interested in changing the status quo need allies in civil society. For public officials who harbor visions of changing the societies they govern, building synergistic ties with subordinate groups may be the best way of circumventing the power of entrenched elites. Conversely, ties to the state give communities that are powerless new leverage in their conflicts with local elites. 
Fox (1992) lays out this possibility in his discussion of the "sandwich strategy," in which reformists within the state apparatus and autonomous civic organizations outside it ally with each other in a mutual struggle against local defenders of the status quo both inside and outside of the state apparatus. Tendler describes an analogous dynamic. In Ceará, "reformists" at the level of state government gave public sector workers and citizens in local communities leverage to counter the power of local political bosses.

Ties to the less privileged are attractive for another related reason. For "normal" Third World states that lack the kind of powerful, autonomous bureaucracies that enabled East Asian industrializers to create synergistic ties with entrepreneurial groups, clientelistic capture is the natural consequence of tight public-private ties involving elites. Ties with the poor and powerless are much less threatening to the institutional integrity of state organizations. Indeed it might be argued that one of the prime advantages of mobilizing ordinary citizens is that mobilization helps balance the inevitable ties with elites and thereby protects the integrity of the state as an institution.

Overall, looking at the political and social structural factors positively associated with synergy is somewhat discouraging. If egalitarian societies with robust public bureaucracies provide the most fertile ground for synergistic state-society relations, most of the Third World offers arid prospects. Since highly inegalitarian social structures presided over by fragile, fragmented government apparatuses are the general rule, it is no wonder that most studies of statesociety relations abound in negative examples. Having begun by rejecting the pessimistic proposition that only areas with exceptional endowments of social capital would be able to enjoy the benefits of synergy, I seem to have fallen into an equally pessimistic appraisal based on a different set of arguments. The conclusion seems bleak given the relatively optimistic cases from which it is derived. It is time to reassess the idea of constructability. Does it still seem possible that synergy can be constructed out of small-scale changes implemented in relatively compressed periods of time, even in adverse environments?

Constructability looks less out of reach if we focus on the content of particular synergistic successes. They suggest that even when the social and political context is inauspicious, creative cultural and organizational innovations can still produce results. Sometimes build- 
ing synergy depends on transforming established worldviews. Sometimes it involves introducing innovative "soft technologies" at the organizational level. Sometimes it involves simply rethinking the nature of the problem that a government agency is trying to address. Any of these strategies can make synergy constructable.

The first cornerstone of constructability is that social structures depend on people's perceptions of themselves and their neighbors and that these perceptions are malleable. Social identities are constructed and reconstructed on a regular basis and can be reconstructed in ways that enhance prospects for synergy. This possibility lies at the heart of the kind of "scaling up" process that Fox and Heller emphasize. In Mexico, villagers who define their interests in terms of defending traditional land rights against infringements by neighbors in adjacent villages can also see themselves as peasants who need to cooperate with other communities in order to defend themselves against landowners and the impersonal forces of commodity markets. In Kerala, members of particular subcastes and religious communities can also see themselves as landless laborers who need to unite across caste and community boundaries in order to get out from underneath the indignities of feudal patron-client relations. New definitions of identity and interest have to be built on new experiences and interaction, but they can be constructed in years rather than decades or centuries.

The second aspect of constructability worth underscoring is that "soft technologies" of organizational design can have large effects. Tendler's careful analysis of the "spillover" effects of the methods used in recruiting agents for Ceará's health care program is an excellent case in point (Tendler forthcoming; see also Tendler and Freedheim 1994). The intricate ways in which hierarchy and latitude are combined in Taiwanese irrigation authorities offer a more complex illustration of how organizational details make a difference. One simple example of the importance of organizational form is the choice between keeping staff in the same local area or transferring them. In India frequent shifts were instituted with the intention of insulating the irrigation bureaucracy and ended up creating a pervasive system of corruption (see Robert Wade 1985). In Taiwan, insulation was secured by other means so that permanent placement of local staff could be used to enhance embeddedness in local communities. ${ }^{14}$ 
Finally, constructing synergy can begin with simple redefinitions of problems. Ostrom's sewer example is a fine case in point. The innovative organizational form of the sewer condominium depended first of all on reconceptualizing "sewers" as consisting of two different, complementary kinds of construction. From there it was possible to formulate a set of synergistic relations based on "coproduction." To take another, very different, example, a key element in allowing synergistic relations of "local state corporatism" to emerge in China was the fiscal redefinition of local governments as the residual claimants on increases in local profits.

The effects of specific innovations are not context free. Anyone who plucks what appears to be a very effective soft technology out of the setting where it was developed and inserts it in a different sociopolitical context is running a risk. Nonetheless, contexts are not immutable. Specific innovations depend on context for their effects, but they also change the contexts in which they are introduced. The effectiveness of Kerala's Industrial Relations Committees (IRCs) depended on the preexisting context of labor relations, but IRCs also helped change that context in a way that enabled Kerala to take better advantage of the human and social capital it had amassed over the years. Even if contextual properties of different settings remain unchanged, they may still be sufficiently similar to make organizational innovations transplantable. Ostrom notes, for example, that the effectiveness of condominium sewer systems is not confined to Northeast Brazil but has transplanted well to Kenya, Paraguay, and Indonesia. There is every reason to believe that synergy is constructable. The trick is to temper the optimism inherent in a constructability perspective with the legitimate pessimism of contextual constraint. Small-scale successes can be achieved even in divided societies without robust public institutions; generalizing them is more difficult. Even in small-scale efforts, it would be foolish to ignore adverse sociopolitical circumstances. Still, prudence should not be an excuse for paralysis. In the end, ignoring the evidence of returns to enterprising and imaginative efforts to construct synergy is probably a worse mistake than underestimating the sociopolitical obstacles to be overcome. 


\section{CONCLUSION}

The value of synergistic strategies is evident. Creative action by government organizations can foster social capital; linking mobilized citizens to public agencies can enhance the efficacy of government. The combination of strong public institutions and organized communities is a powerful tool for development. Better understanding of the nature of synergistic relations between state and society and the conditions under which such relations can most easily be constructed should become a component of future theories of development.

Synergy usually consists of a combination of complementarity and embeddedness. Active citizens are hamstrung unless their governments dependably supply them with inputs that they cannot produce on their own. These range from lumpy tangible products such as dams to essential intangibles such as the rule of law. Citizens contribute local knowledge and experience that would be prohibitively costly for outsiders to acquire. As the beneficiaries of the final product, community members can also contribute their time at implicit wages that public employees should not be forced to match. These obvious complementarities provide a potential basis for synergy. Complementarities create the potential but do not provide an institutional basis for realizing it. Most examples of synergy involve concrete ties connecting state and society which make it possible to exploit complementarities. Norms of trust built up from intimate interaction are not restricted to relations within civil society. People working in public agencies are closely embedded in the communities they work with, creating social capital that spans the public-private divide.

Pre-existing endowments of social capital are valuable resources in the construction of synergistic relations, but they do not appear to be the decisive scarcity. Communities that enjoy the benefits of synergy do not necessarily enjoy exceptional prior endowments of social capital. More crucial in practice is the question of "scaling up" existing social capital to create organizations that are sufficiently encompassing to effectively pursue developmental goals.

A competitive political system helps overcome barriers to synergy, as long as the means of competition are constrained by some set of mutually recognized rules. Egalitarian social structures and 
robust bureaucracies also facilitate its emergence. The rarity of this combination of circumstances in the Third World does not, however, make joint state-society projects unattainable chimeras. Small-scale successes are constructable even within broader contexts that are adverse. Even in class-divided societies suffering under disorganized, authoritarian governance, innovative institutional tactics can foster synergy on a limited scale.

The vision of synergy that has been presented here, however preliminary, has strong implications for both theory and practice. Theoretically, it reinforces the call for an approach to development that is framed in the broadest institutional terms. Nothing else will capture the complicated interactions among social identities, informal norms and networks and formal organizational structures that are involved in creating synergy. For explanations of development to continue to exclude such institutional factors because they do not lend themselves to "well-behaved growth models" is inexcusable. Synergy is too potent a developmental tool to be ignored by development theories. Like social capital, it magnifies the socially valued output that can be derived from existing tangible assets but requires minimal material resources in its own creation .

On the practical side, this analysis implies that those interested in fomenting social capital, even among groups that are normally excluded and oppressed, should not automatically assume that "the state is the enemy." The state may often be the enemy, but only in exceptional circumstances is it monolithically the enemy. Even in relatively authoritarian regimes, alliances with "reformists" within the state can offer resources to popular organizations that are unavailable anywhere else. The implications for "reformists" working with or inside governments are, as we would expect, complementary. The image of the good bureaucrat-carefully insulated from constituents-has its usefulness, but openness to the role of the "coproducer," whether of sewer systems or social capital, may be the best way to increase effectiveness and ultimately the best way to preserve the integrity of increasingly besieged public institutions.

Finally, there are implications for researchers. While it is always fun and often useful to expose the perfidies of public sector actors, this kind of news is already in oversupply. What is needed is more research on positive cases. There are many innovative efforts that cross "the great public-private divide," but they are scattered. Inno- 
vators in one area are likely to be unaware of similar efforts elsewhere. Systematic investigation and comparison of cases across diverse sectors and contexts would be a boon to those in search of "soft technologies" to apply to concrete problems. Research has an important role to play in diffusing the idea that synergy is a real possibility for Third World countries trying to enhance the welfare of their citizens.

\section{NOTES}

I would like to thank all of the participants at the May 1995 Conference of the Economic Development Working Group, Social Capital and Public Affairs Project for their extremely useful feedback on an earlier version of this paper, especially Guillermo O'Donnell, whose comments at the conference were particularly important in reshaping my thinking. My greatest debt is, obviously, to the five authors whose papers precede this one. At the same time, 1 should make it clear that none of them can be held responsible for the interpretations I have imposed on their work.

1. It goes without saying that what often passes for the rule of law in Third World countries is simply the invocation of universalism to mask using the repressive power of the state in the interests of the powerful. Nonetheless, even a flawed approximation of a universalistic rule of law is a potent collective good from the point of view of the powerless.

2. Tendler's work draws in turn on the research of her students: Amorim (1993), Damiani (1993), Freedheim (1993), and Ruth Wade (1993).

3. In addition to Lam, see also Moore (1989: 1741), who says that Taiwan's irrigation system "is widely admired and is perhaps the most efficient in the world."

4. This kind of embeddedness is, as Thorbecke (1993) points out, a feature of Taiwan's highly productive agriculture more generally. The farmers' associations which were a key institutional feature in original efforts to increase agricultural productivity in Taiwan constituted "a good example of a successful GONGO (a hybrid organization blending together characteristics of a Government institution and an NGO)" (Thorbecke 1993: 597). At their origins, the farmers' associations were an arm of the government's Joint Commission for Rural Reconstruction and Development. The associations facilitated the ability of extension agents to channel the results of agricultural research to farmers. They were channels for supervised credit originating in the state apparatus as well as enabling joint buying of inputs and selling of outputs.

5. "Mothers would not answer their knocks on the door, or would hide their children when the agent crossed the doorstep" (Tendler forthcoming: 59). 
6. This description is based on interviews done in Tan Chanh Hiep Commune, Hoc Mon District, in August 1994 with local organizers of the credit scheme and loan recipients, plus the information contained in three brief reports produced by the IER: "The Poverty Issue in Ho Chi Minh City and the First Results of the Credit Savings Model" (December 1993); "Preliminary Report on Implementation of the Project 'Credit Savings' for the Poor-First Year-Tan Chanh Hiep Commune" (May 1994); and "Preliminary Report on 1 Year Implementation of the Project 'Credit-Savings' in Tan Chanh Hiep Commune Branch" (June 1994).

7. See, for example, Shanmugam (1991); Myrada (1992).

8 . Indeed the analogies between the market-oriented socialist version and the established capitalist version are striking. Oi (1992: 119), for example, notes that in the localities she studied, "The strategy of selective support of certain enterprises is reminiscent of Japan's administrative guidance."

9. The concepts of "coproduction" and synergy are very closely related. Talking about "coproduction" tends to focus attention on outputs of goods and services, whereas "synergy" shifts attention more to the social and institutional consequences of joint action across the public-private divide. Even in this respect, however, the difference is not clear-cut. Fox, for example, talks about "coproduction" of social capital.

10. Burawoy's description of the coal miners of Vorkuta, on the other hand, shows that higher levels of mobilization can at least partially compensate for the decay of public institutions. The coal miners could not turn the tide of "economic involution," but their exceptional levels of mobilization did slow the pace of decline and give the community more time to adjust.

11. Unbridled individual maximization is not only detrimental to developmental performance, but also undermines trust and social capital among the sectors of civil society that are connected to the state. Instead of reinforcing the efficacy of private sector associations and expanding their scope, it encourages the primacy of individual ties to particular bureaucrats and undercuts associational life.

12. The discussion by Tendler and Freedheim (1994) of health care workers is an exception.

13. Lack of invidious distinctions between local public sector workers and the constitutents of the projects they work on may also facilitate synergy. The local irrigation officials in Taiwan are more economically secure than the average farmers, but their economic position probably lies somewhere in between the average farmer and the more affluent members of the communities they deal with. Lam contrasts their position with that of the low-status patrollers in the South Asian context. Likewise, Tendler's health agents are definitely the economic and political equals of the people they serve.

14. Robert Wade (1982) makes the same point in contrasting the organization of irrigation in Korea and India. 


\section{REFERENCES}

Amorim, Monica Alves. 1993. "Lessons on Demand: Order and Progress for Small Firms in Ceará, Brazil." M.A. thesis, Department of Urban Studies and Planning, MIT, Cambridge, Mass., May.

Amsden, Alice. 1989. Asia's Next Giant: South Korea and Late Industrialization. New York: Oxford University Press.

Coleman, James. 1990. Foundations of Social Theory. Cambridge, Mass.: Harvard University Press (Belknap).

Damiani, Octavio. 1993. “Learning from Collective Experience: Successful Small Farmer Associations in Northeast Brazil." M.A. thesis, Department of Urban Studies and Planning, MIT, Cambridge, Mass., June.

Evans, Peter. 1995. Embedded Autonomy: States and Industrial Transformation. Princeton, N.J.: Princeton University Press.

Fox, Jonathan. 1992. The Politics of Food in Mexico: State Power and Social Mobilization. Ithaca, N.Y.: Cornell University Press.

1994. "The Difficult Transition from Clientelism to Citizenship: Lessons from Mexico." World Politics 46, 2 (January): 151-84.

Freedheim, Sarah. 1993. "Why Fewer Bells Toll in Ceará: Success of Community Health Worker Program in Ceará, Brazil." M.A. thesis, Department of Urban Studies and Planning, MIT, Cambridge, Mass., June.

Heller, Patrick. 1994. "The Politics of Redistributive Development: State and Class in Kerala, India." Ph.D. dissertation, Department of Sociology, University of California, Berkeley, November.

Johnson, Chalmers. 1982. MITI and the Japanese Miracle: The Growth of Industrial Policy, 1925-1975. Stanford, Calif.: Stanford University Press.

Lam, Wai Fung. 1994. "Institutions, Engineering Infrastructure, and Performance in the Governance and Management of Irrigation Systems: The Case of Nepal." Ph.D. dissertation, School of Public and Environmental Affairs and Department of Political Science, Indiana University, Bloomington.

Moore, Michael P. 1989. "The Fruits and Fallacies of Neoliberalism: The Case of Irrigation." World Development 17, 11: 1733-50.

Myrada. 1992. The Myrada Experience: Alternative Management Systems for Savings and Credit of the Rural Poor. Bangalore, India: Myrada.

Nugent, Jeffrey B. 1993. “Between State, Market and Households: A Neoinstitutional Analysis of Local Organizations and Institutions." World Development 21, 4: 623-32.

O'Donnell, Guillermo. 1993. “On the State, Democratization and Some Conceptual Problems: A Latin American View with Glances at Some Postcommunist Countries." World Development 21, 8: 1355-69.

Oi, Jean. 1992. "Fiscal Reform and the Economic Foundations of Local State Corporatism in China." World Politics 45, 1 (October): 99-126. 
Okimoto, Daniel. 1989. Between MITI and the Market: Japanese Industrial Policy for High Technology. Stanford, Calif.: Stanford University Press.

Putnam, Robert. 1993a. Making Democracy Work: Civic Traditions in Modern Italy. Princeton, N.J.: Princeton University Press.

1993b. "The Prosperous Community." American Prospect, no. 13 (Spring): 35-42.

Shanmugam, Bala. 1991. "Socio-Economic Development through the Informal Credit Market." Modern Asian Studies 25, pt. 2 (May): 209-25.

Judith Tendler. 1993. "Tales of Dissemination of Small-Farm Agriculture: Lessons for Institution Builders." World Development 21, 10: 1567-82.

. 1995. "Social Capital and the Public Sector: The Blurred Boundaries Between Private and Public." Paper presented to the American Academy of Arts and Sciences Conference of the Economic Development Working Group, Social Capital and Public Affairs Project, Cambridge, Mass., May.

Forthcoming. Good Government in the Tropics. Baltimore, Md.: Johns Hopkins University Press.

Tendler, Judith, and Sarah Freedheim. 1994. "Bringing Hirschman Back In: A Case of Bad Government Turned Good." Subsequent version published as "Trust in a Rent-Seeking World: Health and Government Transformed in Northeast Brazil." World Development 22, 12: 1771-92.

Thorbecke, Erik. 1993. "Impact of State and Civil Institutions on the Operation of Rural Markets and Nonmarket Configurations." World Development 21, 4: 591-605.

Wade, Robert. 1982. Irrigation and Agricultural Politics in South Korea. Boulder, Colo.: Westview Press.

1985. "The Market for Public Office: Why the Indian State Is Not Better at Development." World Development 13, 4: 467-97.

1990. Governing the Market: Economic Theory and the Role of Government in Taiwan's Industrialization. Princeton, N.J.: Princeton University Press.

Wade, Ruth. 1993. "Dry Solutions for Drought Relief: Institutional Innovations in Relief Delivery in Ceará, Brazil." M.A. thesis, Department of Urban Studies and Planning, MIT, Cambridge, Mass., June.

World Bank. 1993. The East Asian Miracle: Economic Growth and Public Policy (A World Bank Policy Research Report). New York: Oxford University Press. 